\title{
FIGURAÇÕES DO AMOR LÉSBICO EM AMORA DE NATÁLIA BORGES POLESSO
}

\author{
Representations of lesbian love in Natalia Borges Polesso's Amora
}

\author{
Manuela Rodrigues Santos \\ https://orcid.org/0000-0003-1867-8293 \\ Universidade de Brasília, Programa de Pós-Graduação em Literatura, Brasília, DF, Brasil. \\ 70910-900-ilsecpos@unb.br
}

\begin{abstract}
Resumo: O amor sempre esteve no imaginário e nas preocupações dos seres humanos ao longo dos desafios de viver junto. Contudo, assim com a sociedade muda, a visão de amor e as dinâmicas de relacionamento também se modificam e ganham nos contornos, principalmente na contemporaneidade. Esse processo também impacta o amor lésbico que além de enfrentar as inquietações do amor ainda sofrem com o silenciamento, fruto de uma política do esquecimento produzida por uma sociedade cujo referencial é sempre o homem, branco, heterossexual, cristão, moderno/colonial. Assim, este artigo se propõe a analisar as figurações do amor lésbico, a partir das transformações que o amor apresenta na vida contemporânea e sua relação com o regime da heterossexualidade que impacta a experiência lésbica nos contos: "Minha prima está na cidade", "Como te extraño, Clara", "Diáspora Lésbica" e "Dramaturga hermética" do livro Amora de Natália Borges Polesso (2015). Para tanto, empregou-se como aporte teórico as discussões de Antony Giddens (1993) e de Zygmunt Bauman (2004; 2011a; 2011b), bem como os estudos de Virgínia Maria Vasconcelos Leal (2019), Ochy Curiel (2007; 2013), Tânia Navarro-Swain (2004) e Byang-Chul Han (2011a; 2011b; 2011c).
\end{abstract}

Palavras-chaves: Amor Lésbico. Relacionamento. Natália Borges Polesso.

Abstract: Love has always been in the imagination and concerns of human beings throughout the challenges of living together. However, as society changes, the vision of love and the dynamics of relationships also change and gain in contours, especially in contemporary times. This process also impacts lesbian love which, in addition to facing the concerns of love, still suffer from silencing, the result of a policy of forgetfulness produced by a society whose reference is always a white, heterosexual, Christian, modern/colonial man. Thus, this article proposes to analyze the figurations of lesbian love, from the transformations that love presents in contemporary life and its relationship with the regime of heterosexuality that impacts the lesbian experience in the tales: "Minha prima está na cidade", "Como te extraño, Clara","Diáspora Lésbica" and "Dramaturga Hermética" from the book Amora by Natália Borges Polesso (2015). Therefore, it employs as theoretical input the discussions of Antony Giddens's (1993) and Zygmunt Bauman (2004; 2011a; 2011b), as well as the studies of Virgínia Maria Vasconcelos Leal (2019), Ochy Curiel (2007, 2013), Tânia Navarro-Swain (2004) and Byang-Chul Han (2011a; 2011b; 2011c).

Esta obra está licenciada sob uma Creative Commons - Atribuição 4.0 
Keywords: Lesbian Love. Relationship. Natália Borges Polesso.

\section{A grande transformação do amor}

Desde o momento em que tomou consciência de sua existência, a humanidade sente-se seduzida e fascinada pelo amor e sua influência nas diversas esferas da experiência humana. Nascido sob a égide de Eros, desde cedo, prendeu-se ao desejo, cujas raízes estão na concepção de que o que faz Eros viver é o desejo e este, por sua vez, é carência, é falta. Diz Platão, "como todos aqueles que desejam, desejam o que não é atual nem presente; o que não se tem, o que não se é, aquilo de que se tem falta, eis os objetos do desejo e do amor" (2002, p. 24).

Assim, o amor é apreendido como esperança de captura de algo que confere completude e totalidade ao sujeito numa dinâmica em que, gradativamente, há a fusão entre amor e desejo. O amor é desejo de união com o amado e, como desejo, o amor é lamento, ânsia, busca incessante e infinita. Só amamos porque somos incompletos e essa completude só se realiza no encontro com o outro, numa relação assimétrica do Eu para com o Outro. Desse modo, "o outro, seja quem for, preenche um vazio que o indivíduo sequer necessariamente reconhece - até que a relação de amor seja iniciada. E este vazio tem diretamente a ver com autoidentidade: em certo sentido, o indivíduo fragmentado torna-se inteiro" (GIDDENS, 1993, p. 56).

É com esta perspectiva que se chega ao amor romântico em cuja absorção pelo outro está integrada a orientação característica da "busca", compreendida, portanto, como uma espécie de odisseia na qual a autoidentidade aguarda a sua validação a partir da descoberta do outro. "Tal amor se projeta em dois sentidos: apoia-se no outro e na idealização do outro e projeta um curso do desenvolvimento futuro" (GIDDENS, 1993, p. 56).

No entanto, a Revolução Sexual irá impactar nossa visão de amor ao implementar o que Giddens (1993) chama de sexualidade plástica e, com ela, a reestruturação da intimidade ao lançá-la em outros contextos da sexualidade não só para além do casamento heterossexual, mas também para o domínio do corpo e do desejo através dos grupos até então oprimidos pela heteronormatividade compulsória e pelo gênero. Assim, se num primeiro momento, para uma grande parcela da população, o amor se vinculava à sexualidade do casamento, agora os dois estão vinculados por meio do que Giddens (1993) chama de relacionamento puro,

Uma situação em que se entra em relação social apenas pela própria relação, pelo que pode ser derivado por cada pessoa na manutenção de uma associação com outra e que continua enquanto ambas as partes considerarem que extraem dela satisfação suficientes para cada um individualmente, para nele permanecerem (GIDDENS, 1993, p. 69)

O amor romântico enfraquece-se, dando lugar ao amor confluente que alimenta o relacionamento puro. Ele é um amor ativo, contingente que se desenvolve numa sociedade em que todos têm maiores oportunidades de se tornarem sexualmente realizados. Sua base é, pois, “a aceitação, por parte de cada um dos parceiros, 'até segunda ordem', de que cada um obtenha da relação benefício suficiente que justifique a continuidade" (GIDDENS, 1993, p. 74). Amar é, então, uma tarefa longa, é confiança, comunicação, compromisso, intimidade, dor, prazer.

Anu. Lit., Florianópolis, v. 25, n. 1, p. 87-100, 2020. ISSNe 2175-7917 
No relacionamento puro, a confiança não tem apoio externo, ela se desenvolve com base na intimidade, na capacidade de laço mútuo e na aposta de que o outro é capaz de agir com integridade. "Confiar em alguém significa renunciar às oportunidades de controlá-lo ou de forçar as suas atividades dentro de algum molde particular" (GIDDENS, 1993, p. 155).

Contudo, o advento da Globalização e das tecnologias vem liquefazendo a sociedade contemporânea que não só mergulha num intenso consumismo, mas também gera o que ByungChul Han (2017a) chama de sujeito do desempenho e da produção, empresários de si mesmos que se tornam ao mesmo tempo senhor e escravo, prisioneiro e vigia, vítima e agressor. Acaba explorando a si mesmo numa autocobrança cada vez mais desenfreada que gera um cansaço e esgotamento excessivos. "O cansaço profundo afrouxa as presilhas da identidade. As coisas pestanejam, cintilam e tremulam em suas margens. Tornam-se mais indeterminados, mais permeáveis, e perdem certo teor de sua decisibilidade" (HAN, 2017a, p. 75).

Nesta lógica, o amor parece submeter-se à ditadura do desempenho. A sexualidade é capital que precisa ser multiplicado e o corpo, com seu valor expositivo, transforma-se em mercadoria. "O outro é sexualizado como objeto de excitação. Não se pode amar o outro a que se privou de sua alteridade, só se pode consumi-lo" (HAN, 2017b, p. 27).

Por isso, deparamo-nos com sujeitos que vivem a fragilidade dos vínculos humanos, o sentimento de insegurança que eles inspiram e a angústia entre o desejo de relacionar-se e o medo de fazê-lo. São tempos de relações sociais frágeis que, de forma mais intensa, tornam-se relações mercantilizadas e individualizadas e que irão configurar o que Zygmunt Bauman (2004) chama de amor líquido.

Quando a insegurança sobe a bordo, perde-se a confiança, a ponderação e a estabilidade da navegação. À deriva, a frágil balsa do relacionamento oscila entre as duas rochas nas quais muitas parcerias esbarram: a submissão e o poder absoluto, a aceitação humilde e a conquista arrogante, destruindo a própria autonomia e sufocando o parceiro (BAUMAN, 2004, p. 16).

O amor líquido parece desenhar-se num contexto em que a afinidade desaparece gradativamente numa sociedade de extrema descartabilidade; em que não há amor-próprio e não existem injunções sociais que orientem o amor ao próximo, tornando-o algo vital para uma sociedade cuja sociabilidade entrega-se às tecnologias, criando redes em relações virtuais nas quais as conexões são estabelecidas e cortadas por escolha. Inaugura-se um novo tempo, “o tempo desprovido de instante [...]. Como temporalidade do clique, é desprovido de decisão e de decisibilidade. O instante cede lugar ao clique" (HAN, 2017b, p. 33).

Nessa dinâmica, o amor significa apenas necessidade, satisfação e gozo. Expõe-se como mercadoria numa nudez pornográfica, disponibilizando-se à complexa visibilidade e ao consumo. Para Han (2017c), quando as ações se transformam em operacionais, subordinadas a um processo passível de cálculos, governo e controle, as imagens e as próprias ações tornamse transparentes. São despojadas de "qualquer dramaturgia, coreografia e cenografia, de toda profundidade hermenêutica, de todo sentido, tornam-se pornografias, que é o contato imediato entre imagem e olho" (HAN, 2017c, p.10). Assim, em uma sociedade onde a vida privada é 
exposta nas redes numa busca desesperada através de um fluxo comunicativo de transparência; a sexualidade, o amor e os afetos passam a ser marcados pela evidência, pelo corpo nu.

$\mathrm{O}$ amor transforma-se em pornografia porque não há lugar passível para a negatividade da dor, do sofrimento, da paixão; não há lugar para a lacuna, para o mistério, para as ilusões. "O rosto desnudo, reduzido unicamente a sua expositividade, desprovido de mistério e expressão, é obsceno e pornográfico. $\mathrm{O}$ capitalismo acentua a pornagrifização da sociedade, expondo e exibindo tudo como mercadoria. Ele não conhece nenhum outro uso da sexualidade" (HAN, 2017b, p.61). Desse modo, para Han (2017c), o erótico está na roupa entreaberta, no brilho da pele, na sugestão, na negatividade da interrupção. O pornográfico é liso, não há mistérios, está tudo exposto, esvaziando-se no espetáculo.

Mas, afinal como pensar o amor entre mulheres no interior desse contexto em que os relacionamentos e a busca por amor se modificam ao mesmo tempo em que suas experiências também são atravessadas por questões de gênero e do regime heterossexual?

É importante destacar que o sistema-mundo moderno/colonial, ao conceber a mulher como um ser inferior na dinâmica social, incluindo o que diz respeito ao sentimento do amor, decidiu que seus amores eram insignificantes, contribuindo para um processo de invisibilidade e silenciamento das relações entre mulheres. Por isso, ao narrar as subjetividades encarnadas e sexuadas no feminino, cria-se possibilidades de "catalisar a construção de contextos nos quais seja possível transformar as paixões e os impulsos negativos no 'aqui e agora' das relações concretas. Subjetividades também encarnadas literariamente, negociando seus desconfortos, ao expressar seus afetos" (LEAL, 2019), uma vez que serem representadas também é uma forma de resistência.

Ressalta-se ainda que se ser lésbica está associado ao exercício da sexualidade, é preciso compreender que a prática sexual, os afetos e os relacionamentos nunca terão o mesmo perfil para todas, nunca responderá as mesmas expectativas com os mesmos resultados. Como diz Navarro-Swain,

Pressente-se uma busca e um conhecimento do próprio corpo que é utilizado no prazer de outrem e de si mesma. Sua força e intensidade dependem das pessoas, assim como qualquer relação. A sedução, o contato, o namoro, o toque, o cheiro são desdobramentos da emoção. Humana emoção, troca de humores, erótica reinventada $(2004$, p. 6).

Nessa perspectiva, a proposta de estudo desse artigo consiste em analisar as figurações do amor lésbico a partir das transformações que o amor vem apresentando na contemporaneidade, bem como sua relação com outras estruturas que impactam a experiência lésbica por meio da análise dos contos: "Minha prima está na cidade", "Como te extraño, Clara", "Diáspora lésbica" e "Dramaturga hermética", que compõem o livro Amora de Natália Borges Polesso (2015). Para tanto, empregou-se como aporte teórico as discussões em torno do amor confluente proposto por Antony Giddens (1993) e do amor líquido de Zigmunt Bauman (2004; 2011a; 2011b); as reflexões sobre o ser humano no século XXI de Byung Chul Han (2017a; 2017b; 2017c) e as contribuições de Tânia Navarro-Swain (2004), Virgínia Maria

Anu. Lit., Florianópolis, v. 25, n. 1, p. 87-100, 2020. ISSNe 2175-7917 
Vasconcelos Leal (2019) e Ochy Curiel (2007; 2013).

\section{Figurações I: o amor confluente e a arte de viver}

Para Giddens, "o amor confluente presume igualdade na doação e no recebimento emocionais, e quanto mais for assim, qualquer laço amoroso aproxima-se muito mais do protótipo do relacionamento puro" (1993, p. 73). Nesse sentido, o amor só se desenvolve no momento em que aumenta a intimidade, em que cada parceiro está preparado para manifestar preocupações e necessidades em relação ao outro e está vulnerável a esse outro.

Assim, em "Minha prima está na cidade", assiste-se à construção desse amor, ao mesmo tempo em que nos deparamos com as angústias da narradora que ainda sofre com o medo do preconceito da sociedade e o impacto disso em sua vida profissional e familiar. Ser lésbica fora do universo particular que ela criou para si ainda é complexo e inquietante para ela: "Aproveitei que a Bruna estava viajando e decidi convidar o pessoal da firma. É que eu nunca tinha falado da Bruna para nenhuma das minhas colegas. Eu trabalho num lugar que não me permite fazer isso" (POLESSO, 2015, p. 74).

A forma como a sociedade impõe o imperativo da heterossexualidade, compreendido por Ochy Curiel (2013) como um regime político que organiza o mundo através da ideologia da diferença sexual, que está na base de instituições como a família, o parentesco, a nacionalidade; além de alimentar o preconceito, a discriminação e a criação de imagens negativas dos sujeitos dissidentes, os levam, muitas vezes, a apresentar dificuldade na aceitação de si mesmo. A percepção de si ocorre na esfera do imaginário heterossexual que é reforçado diariamente através das imagens construídas nos mais variados produtos culturais, dos vários discursos produzidos e da própria linguagem. Emana nesse contexto, pois, o medo de ser identificado com essas imagens ameaçadoras que teme reconhecer como sendo a si mesmo.

Nesse sentido, é interessante como a narradora e Bruna, sua companheira, têm perspectivas diferentes no que tange à construção da autoidentidade e da vivência da sexualidade. Se Bruna tem uma consciência do que é ser uma lésbica e construiu uma autodefinição empoderada de si mesma, a narradora, embora feliz, ainda precisa fazer a caminhada rumo a uma redescoberta de si que promova não só uma espécie de autoaceitação, mas também as ferramentas necessárias para enfrentar o mundo a sua volta, pois, como defende Curiel (2013), é preciso compreender não só a complexidade do lesbianismo como prática sexual e política, mas também que a mulher lésbica tem sido limitada por toda uma normatividade.

Eu vou jantar com os amigos da Bruna, amigos do trabalho. Eles sabem que a gente é um casal, porque a Bruna não tem problemas com isso. Eu tenho. Quer dizer, já tive mais, mas agora consigo lidar até bem com essa questão da sexualidade, claro, dentro da minha cabeça. Não conto para muitas pessoas, tem gente que não precisa saber não faz diferença. Por exemplo, as minhas colegas de trabalho não precisam saber, nem a minha família (POLESSO, 2015, p. 74-75). 
No entanto, mesmo sob as sombras do medo da narradora, a construção do relacionamento entre as duas se dá à medida que ela toma consciência do que sente e da própria existência da relação, marcada pela cumplicidade, pelos afetos, pelos desentendimentos, pelos conflitos, pelo bem-estar, através do compromisso e da confiança que se estabelecem: "Acontece que eu e a Bruna somos uma família, mas eu demorei para entender que éramos" (POLESSO, 2015, p. 75).

Criar um compromisso é desenvolver uma história compartilhada na qual atos e palavras vão consolidando as relações, ao mesmo tempo em que eles geram garantias de felicidade. É, nesse espaço amoroso de mulheres, que se constrói um saber-amar-outro que permite repensar a si e a resignificar seus afetos. Assim, é quando adoece e Bruna cuida dela que finalmente a narradora se sente verdadeiramente em casa, do lado da pessoa que ama e que torna seu mundo completo. Nesse momento, finalmente, compreende que

minha família estava ali, com louças, gripes, montes de cabelo, cheiros de comida caseira, café na cama e banhos quentes, com brigas e pedidos de desculpas, carinhos, amores, cuidados, e era mesmo uma família, até quando ficávamos vendo televisão no domingo de tarde (POLESSO, 2015, p. 75-76).

Se o amor é uma longa caminhada, a narradora revela-nos como ele vai se construindo nas pequenas coisas do quotidiano e nos acordos estabelecidos ao longo do caminho. Amar não é um idílio, sinônimo de um relacionamento ideal e perfeito, como nos fez acreditar o amor romântico. Ao contrário, amar é um fazer e re-fazer constante numa lógica de negociações ativadas pelas amantes.

Eu amo a Bruna e nunca quis magoá-la e nunca vou querer. Temos essa combinação de evitar dizer coisas das quais possivelmente nos arrependeremos mais tarde e nunca, nunca ameaçamos uma a outra com um término de relação a menos que isso seja mesmo uma possibilidade, aliás, mais do que isso, que seja uma vontade legítima para além daquele momento (POLESSO, 2015, p. 76).

A cumplicidade, a comunicação e a intimidade contribuíram para que o amor confluente se consolide como uma possibilidade real de abertura de uma em relação à outra. Já não se busca mais a pessoa especial, mas sim um relacionamento que se sabe não ser perfeito, mas que ambas tentam fazer dar certo, acreditando uma na outra, confiando na potencialidade da relação e do conhecimento das peculiaridades de cada uma das envolvidas. Isso, num processo contínuo de reflexão em que cada passo deve, de certa forma, ser negociado como parte do relacionamento. Mesmo quando se tenta mantê-lo recluso na segurança da casa e longe do mundo.

Depois que elas foram embora, eu fui falar com a Bruna e ela só me disse que em algum momento aquilo teria que mudar, riu do absurdo e disse também que a verdade teria sido indolor, talvez, mas não tinha certeza, talvez estivesse errada. O fato é que continuamos tentando (POLESSO, 2015, p. 79).

Já em "Como te extraño, Clara", a construção do relacionamento se insere em outra Anu. Lit., Florianópolis, v. 25, n. 1, p. 87-100, 2020. ISSNe 2175-7917 
questão muito comum nos amores lésbicos: uma espécie de heterossexualidade como uma etapa quase obrigatória, imposta por uma sociedade que, mesmo vivendo uma sexualidade plástica, ainda se sustenta na heteronormatividade como modus operandi dos relacionamentos considerados "normais" e "naturais". Assim, Fernanda "amava Clara. Tinha se apaixonado. Eduardo era apenas a sombra de uma vida que ela teimava em manter" (POLESSO, 2015, p. 124).

Fernanda, casada com Eduardo e mãe do adolescente Rafael, vê-se apaixonada por Clara, uma menina mais nova do que ela, mas que lhe abre a possibilidade de viver intensamente seus sentimentos, seus desejos e suas paixões, e passa a viver uma vida dupla que gradativamente a lança num mar de angústias e incertezas quanto ao futuro: de um lado a calma, a ordem e a segurança da relação com Eduardo; do outro o caos, as incertezas e o estranho da relação com Clara.

Fernanda fechou os olhos e deixou que o pulmão se enchesse. Enquanto o ar mexia nos pensamentos que se dispunham no peito e na sua cabeça, ela tentava organizar, de alguma maneira que fizesse sentido, os últimos eventos da sua vida. Porém nada parecia querer tomar um lugar próprio, um lugar onde o peso não fosse incômodo ou não arrastasse o andar dos demais lances do destino. Sua vida tinha chegado a um ponto nevrálgico, a um nó tão enrolado que só se resolveria se cortado, desatar não era opção (POLESSO, 2015, p. 123).

O amor confluente introduz a satisfação e a felicidade sexuais como elemento importante do relacionamento e transforma a realização do prazer sexual recíproco em um momento-chave na manutenção ou dissolução do relacionamento. Por isso, a angústia se agiganta em Fernanda. Estar feliz com Clara seria suficiente para abrir mão da vida que ela construíra até agora? "Talvez a vida seja assim mesmo, dependendo das escolhas que se faz, não há como retroceder, e o caminho que Fernanda tinha traçado até ali não permitia a presença de Clara. Era o que passava pela sua cabeça" (POLESSO, 2015, p. 127-128).

Contudo, o que Fernanda parecia não ter coragem de fazer, o destino encontra novos caminhos: ao sofrer um grave acidente de trânsito, Eduardo descobre não só a existência de Clara, mas toda a história da relação entre as duas. Com isso sua vida muda abruptamente já que ele sai de casa sem dizer nada, deixando-a nesse novo mundo que a princípio lhe parece estranho e assustador. "Mas, a aparente facilidade com a qual ele tinha lidado com a situação e deixado a casa sinalizava insatisfação mútua" (POLESSO, 2015, p. 128).

Mesmo sendo lançada no desafio de construir um novo relacionamento: "Agora, é isso. Nós duas. Eu, parte quebrada, tu com essa cara de susto... E o guri” (POLESSO, 2015, p. 129), Fernanda está disposta a ser feliz com Clara. Ainda que a velocidade das mudanças a faça demorar a dar algum sentido para as coisas, principalmente quando ouve seu filho, com uma naturalidade que a assusta, tratar Clara como sua namorada ao questionar se as duas iriam morar juntas. Presa no sistema da heterossexualidade obrigatória que apaga e silencia as mulheres lésbicas, Fernanda tem consciência de que "há afetos positivos e negativos, custos, prazeres e satisfações associados a esse estar no mundo, vinculados a certas direções que nossa forma de amar e de viver pode assumir" (LEAL, 2019). Todavia, a vivência livre e sem culpas de sua

Anu. Lit., Florianópolis, v. 25, n. 1, p. 87-100, 2020. ISSNe 2175-7917 
relação com Clara revela que é possível reinventar outras formas de amar, novas esperanças e novas práticas políticas.

A vida pessoal tornou-se, pois, um projeto aberto, criando novas demandas e novas ansiedades. E o amor, muito mais do que uma identificação projetiva do Eu, é a possibilidade de uma experiência do outro em sua alteridade e, consequentemente, a possibilidade de construção de um relacionamento em que ambos se considerem prontos para o convívio, para o mistério e o enigmático, para o novo e para os desafios que perpassam a construção diária de uma relação. Como afirma Paloma Vidal no prefácio do livro, a construção da relação, suas mudanças, suas estranhezas, em seu constante devir, se abre à possibilidade "pequena e persistente, que quando menos esperamos se torna real, com uma naturalidade que primeiro surpreende e depois não mais, alegrando-nos como um beijo que vira sorriso dentro da nossa boca" (POLESSO, 2015, p. 01).

\section{Figurações II: solidão, fim de quem ama}

Em contrapartida ao amor confluente e sua tentativa de erigir relacionamentos puros, deparamo-nos com sujeitos abandonados a uma sensação de insegurança que anseiam pela segurança do convívio e pela mão amiga com que possam contar em um momento de aflição. Desesperados por relacionar-se, entretanto, desconfiados da condição de estar ligado e das implicações que isso pode lhes causar. Assim,

Você busca o relacionamento na expectativa de mitigar a insegurança que infestou sua solidão; mas o tratamento só fez expandir os sintomas e agora você talvez se sinta mais inseguro do que antes, ainda que essa 'nova e agravada' insegurança provenha de outras paragens (BAUMAN, 2004, p. 15).

Nessa perspectiva, em “Diáspora lésbica”, é interessante como essa sensação de incerteza, de conexão e de desconexão já se instaura no título do conto, ao se pensar a diáspora como movimento e de certa forma como um sentimento de não pertencimento que parece envolver as personagens. Cada uma vive a sua diáspora interior ao mesmo tempo em que os espaços frequentados tentam criar a ilusão de unidade que se esfacela quando "decidiram fazer programas mais caseiros" (POLESSO, 2015, p. 147) e o bar da Tânia, importante ponto de encontro da comunidade LGBTQ+, fechou.

O conto centra-se no encontro entre as amigas, Juli, Lea, Zica Bea e Preta, que começam falando sobre o relacionamento de Chica com "uma hétero e que precisava se arrumar melhor, porque a mulher era uma socialaite da cidade" (POLESSO, 2015, p.138). Fato que parecia justificar a transformação na forma de se vestir e de se comportar de Chica. Em seguida, passam a falar de Inês, caracterizada pelo grupo como uma predadora, pronta a atacar a qualquer momento. Seu sentido de caça não possuía limites. "A Inês era uma predadora. Enquanto casada, ficava reclusa, mas, toda vez que terminava um relacionamento, um deus nos acuda se instalava, porque ela saía para caçar. E caçava. Matava e levava para casa" (POLESSO, 2015, p. 140).

É nesse cenário que aos poucos vão se descortinando as tentativas de relacionamento

Anu. Lit., Florianópolis, v. 25, n. 1, p. 87-100, 2020. ISSNe 2175-7917 
nesse conturbado mundo líquido, da rapidez e da diluição, em que tudo, inclusive as pessoas, vai se tornando objeto de consumo. Assim, temos Bea e Preta, "um casal incompreensível [...] Relação aberta, ativa e perfeita" (POLESSO, 2015, p. 139), mas que abriga uma gama de incertezas e uma certa possessividade que procura se realizar no controle.

Uma vez, Preta tinha olhado para um casal hétero num bar, na verdade, olhou através deles, estava distraída. Bea não esperou um segundo para armar um barraco, dizendo que não ia transar com eles. Preta não estava entendendo nada e Bea ficava cada vez mais histérica. Até que, sem pensar muito, Preta lhe deu um tapa na cara, levantou do bar e foi embora. No mesmo dia, fizeram as pazes e muito sexo (POLESSO, 2015, p. 139).

A Inês, por sua vez, exemplifica o que Bauman (2004) chama de relação de bolso, isto é, a encarnação da instantaneidade e da disponibilidade numa dinâmica de relacionamentos em que o sujeito está no controle e nele permanece por toda a curta vida da relação, seja com Juli, com Cica, com Rafaela, com a adolescente de dezesseis anos Rita e até mesmo com Aline, namorada de Chica com quem irá flertar. "Algumas horas e drinques depois, a Inês estava descaradamente dando em cima da namorada da Chica, e o pior de tudo, a safada estava correspondendo" (POLESSO, 2015, p. 144).

Nada de apaixonar-se. Em nossas vidas pressionadas pelo tempo instantâneo, erradica-se a necessidade da espera por algo ou alguém. Já não há mais tempo a se perder. Portanto, o amor emerge como algo que precisa ser sempre e novamente construído e reformado a cada dia, a cada hora; constantemente ressuscitado, reafirmado, servido em conformidade com a crescente fragilidade dos vínculos humanos. "Ele precisa gerar sentimentos agradáveis. Ele não é uma ação, uma narração, nem sequer é mais um drama; antes não passa de emoção ou excitação inconsequente" (HAN, 2017b, p.29). Vive-se em um tempo acelerado, sem memória, de renúncia da privacidade em que tudo acontece de forma hiperbólica que reduz o amor a uma única noite de sexo.

Nem precisou fazer esforço para achá-las, estavam se beijando na frente da pia. Aline desviou os olhos, Inês ficou sorrindo. Chica voltou para a mesa, pegou as coisas dela e saiu. Juli foi atrás. [...] Todas as gurias apareceram na esquina onde Juli e Chica estavam sentadas, menos a Inês e a Aline, que, naquela mesma noite, se hospedaram num hotel da cidade (POLESSO, 2015, p. 145-146).

Finalmente Chica e Aline, um relacionamento marcado por um jogo de poder que se manifesta no fato de Aline ser uma socialite e impor sua cosmovisão à Chica que, de alguma forma, passa a seguir as supostas orientações da amada. Há uma projeção do Eu no outro, ocasionando uma espécie de apagamento desse outro. É interessante observar que isso, no entanto, não garante a durabilidade do relacionamento, o que culminará na relação fortuita de Aline com Inês.

Contudo, "por muitos meses, a Chica continuou saindo com a gente. Até que ela voltou com a Aline e com o collant e a maquiagem over. Uma pena, todas concordavam" (POLESSO, 
2015, p. 146-147). Chica parece envolver-se no relacionamento para escapar à aflição da fragilidade e para escapar da solidão. Contudo, diz Bauman (2004, p. 20), "o que se propunha/ansiava/esperava ser um abrigo (talvez o abrigo) contra a fragilidade revela-se sempre como a sua estufa". Têm-se, então, indivíduos concebidos em um mundo próprio, alheio às ambivalências presentes na relação com os outros seres humanos. Além disso, busca-se uma relação com a expectativa de dirimir a insegurança produzida por sua solidão, mas as incertezas do mundo moderno-líquido acabam por expandir os sintomas, já que numa relação é possível sentir-se tão inseguro quanto sem ela, ou pior. Só alteram os nomes dados à ansiedade.

A parceria, portanto, é somente uma coalizão de interesses confluentes e nesse mundo fluido, as pessoas vêm e vão, as oportunidades batem à porta e desaparecem novamente logo após convidadas a entrar. Como consequência, Bea, Preta, Inês, Aline, Chica tendem a fazer coligações flutuantes, frágeis e flexíveis.

Já em "Dramaturga Hermética", a vontade de conectar-se e de entender o vazio interior são os motes que norteiam a relação entre $\mathrm{M}$ e Ana. No entanto, toda a conversa se dá por email, por mais que Ana tente tornar o encontro presencial, $M$ foge, evita encontrá-la. Bauman (2011a) aponta que o mundo líquido-moderno possui uma dupla forma de se relacionar com a realidade sintetizada no binômio on-line/off-line, no qual o primeiro polo caracteriza-se pelo estar dentro da rede, permitindo ligar-se e desligar-se do outro sem riscos. Nessa perspectiva, as relações virtuais emergem como possibilidades românticas, ou não apenas românticas, que surgem e desaparecem numa velocidade crescente e num volume cada vez maior, aniquilandose mutuamente. Isso acaba gerando a sensação de vazio ou de náusea de viver, razão que leva $\mathrm{M}$ a escrever seus e-mails.

E assim, Ana, têm sido meus dias e meus amores, de uma tarde, apenas, exóticos, arredios, ausentes, mórbidos [...] Eu preciso me conectar ao que experimento nos sentidos, Ana. Mas me diz como fazer isso se não tenho sentido nada? Nada me comove (POLESSO, 2015, p. 103-104).

Como sujeito em trânsito, $M$ está em todos os lugares, embora cada vez mais não se sinta pertencente a lugar algum: "Fiquei tanto tempo fora que não pertenço mais a lugar algum, parece que eu sou um objeto, entende? Descolado do mundo, sem identificação com absolutamente nada, que vaga solto na imensidão, na infinitude das possibilidades" (POLESSO, 2015, p. 103). Assim, a falta de ligação com o outro gera a sensação de crise e de culpa, ao mesmo tempo em que a eliminação das distâncias não gera aproximação, ao contrário, parece afastá-la. Diz Bauman (2004, p. 15), “estar num relacionamento significa [...], sobretudo, uma incerteza permanente. Você nunca poderá estar pleno e verdadeiramente seguro daquilo que faz - ou de ter feito a coisa certa ou no momento preciso".

A solidão produz insegurança e os relacionamentos também podem gerá-la: "menti quando disse que não tinha me relacionado com ninguém, me relaciono com alguns desses velhinhos. Eles me pagam cafés e chocolates depois das discussões e me chamam de menina" (POLESSO, 2015, p. 106). Como eles são vistos como investimento, como garantia de segurança e solução dos problemas, parecem um jogo de cara ou coroa, porque estar neles nada

Anu. Lit., Florianópolis, v. 25, n. 1, p. 87-100, 2020. ISSNe 2175-7917 
garante, mesmo sendo "alma gêmea, sensível, virtual em todos os sentidos" (POLESSO, 2015, p. 107).

É importante ressaltar que, embora $\mathrm{M}$ demonstre o desejo de conectar-se, até mesmo como uma alternativa para poder falar numa dimensão em que poder falar é existir, nota-se o medo da possibilidade desta conexão ser séria ou que ela crie vínculos mais fortes. "Estarei fora nos próximos meses, vou à Alemanha. Quando eu voltar, se voltar mesmo, te ligo e tu pode vir numa quarta-feira para um café" (POLESSO, 2015, p. 117). Como se afirmou anteriormente, desde os primeiros e-mails, Ana clama por um encontro presencial, mas $\mathrm{M}$ fica na defensiva até o último momento em que deixa em suspenso tal possibilidade.

Manter-se na rede permite a $\mathrm{M}$ ficar no controle para conectar ou desconectar. Estar online permite um melhor gerenciamento das relações, principalmente pela ausência das contradições que rondam a vida off-line. Como diz Bauman (2011a),

O mundo on-line, por outro lado, cria uma multiplicação infinita de possibilidades de contatos plausíveis e factíveis. Ele faz isso reduzindo a duração desses contatos e, por conseguinte, enfraquecendo os laços, muitas vezes impondo tempo - em flagrante oposição à sua contrapartida off-line, que, como é sabido, se apóia no esforço continuado de fortalecer os vínculos, limitando severamente o número de contato à medida que eles ampliam e se aprofundam (BAUMAN, 2011a, p. 63)

Mas tudo tem um preço. Manter-se em movimento, em alta velocidade, antes uma aventura estimulante, torna-se uma tarefa cansativa: "Movimento forçoso, miserento. Me sinto um títere, um pouco curvado talvez pelo peso das asas desenhadas ou talvez, porque as mãos que me guiam estejam enfastiadas. Eu estou enfastiada" (POLESSO, 2015, p. 113). Como consequência, $\mathrm{M}$ fecha-se em si mesma, encenando uma espécie de dramaturgia hermética, tornando-se uma pessoa solitária numa multidão de solitários. "Estamos todos em uma solidão e numa multidão ao mesmo tempo" (BAUMAN, 2011b).

Por fim, nesse jogo constante de medo e insegurança, de desejo e vontade, do eu e do outro, o amor líquido lança sua sombra sobre o viver junto compreendido sob a lógica do "é por causa de", mantendo, assim, todas as opções abertas e ilimitadas, embora não dê garantia alguma. Por isso,

as pontes são inúteis, a menos que cubram totalmente a distância entre as margens - mas no viver juntos a outra margem está envolta na neblina que nunca se dissipa, que ninguém tenta dissolver nem tenta afastar. Não há como saber o que se vai ver quando (se) a névoa se dispersar - nem se de fato existe alguma coisa encoberta (BAUMAN, 2004, p. 23).

Então, nesses tempos de fluidez e incertezas, a solidão seria o destino final de quem ama? Como saber? Em tempos líquidos modernos, relacionar-se é um desafio, é um navegar de uma margem a outra, é compartilhar as agruras e as alegrias da viagem, muito mais do que construir pontes. Da mesma forma, pensar o processo de construção de laços entre mulheres também significa, segundo Curiel (2007), entender que são corpos que constroem a resistência e a 
oposição à desigualdade que produz o patriarcado, corpos que têm imaginado e criado outras relações sociais, outros paradigmas, outros mundos, mesmo sob a confluência dos principais pilares do amor líquido: relacionamento e fluidez.

\section{Considerações finais}

Como se pôde observar, pensar os amores lésbicos, no contexto aqui apresentado, é fazêlo de dois lugares. Por um lado, tem-se o debate em torno das configurações do amor e dos relacionamentos que caracterizam a sociedade do cansaço e da transparência em tempos líquido-modernos; por outro, têm-se as reflexões sobre o amor lésbico e sua dinâmica entre visibilidade e invisibilidade que ainda marcam essas relações. Descobrir sua sexualidade, sentir um desejo intenso e ter prazer, apaixonar-se pela primeira vez, compreender quem realmente se é e ter coragem de tentar ser feliz. Eis as dinâmicas que estão na base desse amor.

Os contos analisados, por sua vez, reiteram a existência dessas mulheres que não só vivem numa sociedade que transformou tudo, inclusive as relações humanas, em mercadoria, mas também sofrem o desafio de viver num contexto que ainda condena a forma de amar daqueles que fogem "à norma". As lutas parecem agigantar-se, pois ao lado do medo, das angústias e das pelejas de relacionar-se no século XXI, precisam enfrentar as incertezas, as aflições ligadas ao processo de saber quem é e como compreender e viver sua sexualidade. Por isso, afirma Curiel (2007), o lesbianismo não se entende somente como uma prática sexual, mas também como uma atitude de vida, uma ética emoldurada em uma proposta política que implica tanto a compreensão da heterossexualidade como um regime político, quanto a necessidade de se desejar e construir a liberdade e a autonomia das mulheres em todos os planos por meio da criação de laços entre elas, sem hierarquias, nem relações de poder.

Desse modo, ao lado da tentativa de se construir relacionamentos puros ou de se lançar nos frágeis laços das relações em tempos líquidos, o amor lésbico ainda enfrenta as agruras e as violências do preconceito e da discriminação, cônscio de mais um desafio que precisa ser vencido em sua longa caminhada: ser reconhecido e respeitado. É claro que amar não é forçosamente idílico, longe disso. Mas, que podemos ser felizes o quanto for possível ser neste mundo.

\section{Referências}

BAUMAN, Zygmunt. Amor líquido. Trad. de Carlos Alberto Medeiros. Rio de Janeiro: Jorge Zahar, 2004.

BAUMAN, Zygmunt. 44 cartas do mundo moderno líquido. Trad. de Vera Pereira. Rio de Janeiro: Jorge Zahar, 2011a.

BAUMAN, Zygmunt. Diálogos com Zygmunt Bauman. [Entrevista concedida a] CPFL Cultura e o Seminário Fronteiras do Pensamento, Instituto CPFL, Campinas, 16 ago. 201 b. Disponível em: http://www.institutocpfl.org.br/2011/08/16/dialogos-com-zygmunt-bauman/. Acesso em: $18 / 05 / 2020$. 
CURIEL, Ochy. La nación heterosexual: análisis del discurso jurídico y el régimen heterosexual desde la antropología de la dominación. Bogotá: Brecha Lésbica y en la Frontera, 2013.

CURIEL, Ochy. El lesbianismo feminista: una propuesta política transformadora. América Latina en movimiento [online], Quito, 14 mai. 2007. Disponível em: https://www.alainet.org/es/active/17389. Acesso em: 08/05/2020.

GIDDENS, Anthony. A transformação da intimidade: sexualidade, amor e erotismo nas sociedades modernas. Trad. de Magda Ramos. São Paulo: Unesp, 1993.

HAN, Byung-Chul. Sociedade do Cansaço. Trad. de Enio Paulo Giachini. Petrópolis/RJ: Vozes, 2017a.

HAN, Byung-Chul. Agonia de Eros. Trad. de Enio Paulo Giachini. Petrópolis/RJ: Vozes, $2017 b$.

HAN, Byung-Chul. Sociedade da Transparência. Trad. de Enio Paulo Giachini. Petrópolis/RJ: Vozes, 2017c.

LEAL, Vírginia Maria Vasconselos. Por amor a elas, por amor ao mundo. Grupo de Estudos em Literatura Brasileira Contemporânea, Brasília, 28 jul. 2019. Disponível em: https://gelbcunb.blogspot.com/2019/07/por-amor-elas-por-amor-ao-mundo.html. Acesso em: 02/05/2020.

NAVARRO-SWAIN, Tânia. O que é lesbianismo. São Paulo: Brasiliense, 2004.

PLATÃO. O banquete. Trad. de Maria Teresa S. de Azevedo. Lisboa: Edições 70, 2002.

POLESSO, Natália Borges. Amora. Porto Alegre: Não Editora, 2015.

\section{NOTAS DE AUTORIA}

Manuela Rodrigues Santos (manurodrigues2512@gmail.com) é licenciada em Letras Português-Francês (UFS), Mestre em Sociologia (UFS) e Doutoranda do Programa de PósGraduação em Literatura (PÓSLIT/UnB). É professora de Língua Portuguesa e suas respectivas literaturas do Instituto Federal de Sergipe - Campus São Cristóvão. Desenvolve estudos ligados a Teorias da Narrativa; Estudos de Gênero e Crítica Literária Feminista; Teoria e Políticas Queer e Representações de Gênero e Diversidade Sexual na Literatura Brasileira Contemporânea.

\section{Como citar esse artigo de acordo com as normas da revista}

SANTOS, Manuela Rodrigues. Figurações do amor lésbico em Amora de Natália Borges Polesso. Anuário de Literatura, Florianópolis, v. 25, n. 1, p. 87-100, 2020.

\section{Contribuição de autoria}

Não se aplica.

\section{Financiamento}

Não se aplica. 
Consentimento de uso de imagem

Não se aplica.

Aprovação de comitê de ética em pesquisa

Não se aplica.

Licença de uso

Este artigo está licenciado sob a Licença Creative Commons CC-BY. Com essa licença você pode compartilhar, adaptar, criar para qualquer fim, desde que atribua a autoria da obra.

\section{Histórico}

Recebido em: 25/11/2019

Revisões requeridas em: 15/05/2020

Aprovado em: 22/05/2020 